Check for updates

Cite this: RSC Adv., 2017, 7, 36929

Received 28th April 2017 Accepted 15th July 2017

DOI: 10.1039/c7ra04806h

rsc.li/rsc-advances

\section{Protic salt-based nitrogen-doped mesoporous carbon for simultaneous electrochemical detection of $\mathrm{Cd}(\mathrm{II})$ and $\mathrm{Pb}(\mathrm{II})$}

\author{
Danfeng Qin, $\dagger^{\text {ae }}$ Ruiyu Xu, $\dagger^{\text {ae }}$ Hangjia Shen, ${ }^{\text {ae }}$ Xamxikamar Mamat, ${ }^{a}$ Le Wang, ${ }^{\text {ae }}$ \\ Shanshuang Gao, ${ }^{a}$ Ying Wang, ${ }^{\text {ae }}$ Nuerbiya Yalikun, ${ }^{\text {ae }}$ Thomas Wagberg, ${ }^{\text {tb }}$ \\ Shiguo Zhang, ${ }^{c}$ Qunhui yuan, ${ }^{* d}$ Yongtao $\mathrm{Li}^{\mathrm{a}}$ and Guangzhi Hu (D) *ae
}

\begin{abstract}
Nitrogen-doped mesoporous carbon (NMC) derived from a single small-molecule protic salt $(p-$ phenylenediamine bisulfate) is used for sensing toxic heavy metal ions. Using Nafion, bismuth and NMC to anchor the glassy carbon electrode surface, the fabricate electrode shows high sensitivity for detecting $\mathrm{Cd}(॥)$ and $\mathrm{Pb}(॥)$. The limits of detection $(\mathrm{S} / \mathrm{N}=3)$ are estimated to be $0.3 \mu \mathrm{g} \mathrm{L}^{-1}$ for $\mathrm{Cd}(॥)$ and $0.4 \mu \mathrm{g} \mathrm{L}^{-1}$ for $\mathrm{Pb}(\Perp)$, respectively, which are 10 and 25 times lower than the maximum acceptable content for drinking water recommended by the WHO. Furthermore, the sensor is successfully used to analyze $\mathrm{Cd}(॥)$ and $\mathrm{Pb}(॥)$ in tap-water with high anti-interference capability and good recovery.
\end{abstract}

\section{Introduction}

Toxic heavy metals pose a serious threat to both the environment and human health, because of their strong toxicity, ability to accumulate in biological systems and long metabolic cycles. ${ }^{1}$ Among the heavy metals, $\mathrm{Cd}(\mathrm{II})$ and $\mathrm{Pb}$ (II) are two common pollutants, which are harmful to mental health, the central nervous system, deleterious blood composition as well as other tissues and organs. ${ }^{2}$ Hence, it is urgent to dynamically monitor $\mathrm{Pb}(\mathrm{II})$ and $\mathrm{Cd}(\mathrm{II})$ at trace levels. With the aim of realizing accurate and reliable determination of heavy metals in environmental samples, different techniques such as fluorescence $^{3}$ and inductively coupled plasma mass spectroscopy (ICP-MS) ${ }^{4}$ have been applied. However, these methods normally need professional operation and they are costly and/or require complex instruments. On the contrary electrochemical detection methods are time efficient, sensitive and use low cost equipment. In particular, anodic stripping voltammetry (ASV) represents a powerful tool for analyzing trace metals due to the effective accumulation

${ }^{a}$ Key Laboratory of Chemistry of Plant Resources in Arid Regions, State Key Laboratory Basis of Xinjiang Indigenous Medicinal Plants Resource Utilization, Xinjiang Technical Institute of Physics and Chemistry, Chinese Academy of Sciences, Urumqi 830011, Xinjiang, China. E-mail: guangzhihu@ms.xjb.ac.cn

${ }^{b}$ Department of Physics, Umea University, 90187 Umea, Sweden. E-mail: thomas. wagberg@umu.se

${ }^{\circ}$ Department of Chemistry and Biotechnology, Yokohama National University, 79-5 Tokiwadai, Hodogaya-ku, Yokohama 240-8501, Japan

${ }^{d}$ Harbin Institute of Technology, Shenzhen 518055, China. E-mail: yuanqunhui@hitsz. edu.cn

${ }^{e}$ University of Chinese Academy of Sciences, Beijing 100049, China

$\dagger$ This authors contributed equally to the work. of the target ions, ${ }^{5}$ which should be noted relies strongly on the sensing material deposited on the working electrode surface. ${ }^{6}$

Nitrogen-doped mesoporous carbon (NMC) has shown excellent physical and chemical properties, such as abundant pore structure, large surface area, and low density, ${ }^{7}$ making it frequently applied in lithium batteries, ${ }^{8}$ fuel cells, ${ }^{9}$ supercapacitors, ${ }^{10}$ catalyst supports, ${ }^{11}$ separation processes ${ }^{12}$ and sensing. ${ }^{13}$ To detect heavy metals, NMC is hypothesized to exhibit remarkable performance because the mesoporous structure not only provides efficient diffusion and mass transfer for heavy metal ions, but also contains a large amount of electron-donating nitrogen atoms which can improve the performance of sensor. ${ }^{14,15}$ For example, Cui et al. demonstrated a nitrogen-doped porous carbon was synthesized with Al-based organic gel template for detection of Cd(II) by ASV with good stability and excellent selectivity. ${ }^{16}$

Normally, mesoporous carbon is produced based on the sacrifice template method, but the method is multistep, and time-consuming. ${ }^{7,17-19}$ For example, Shen et al. recently reported a $\mathrm{MgO} /$ ordered mesoporous carbon composite that could be applied for determination of $\mathrm{Pb}(\mathrm{II}){ }^{20}$ The casting template method used for the preparation of ordered mesoporous carbon is complex, including SBA-15 (as template) preparation, infiltration of the sucrose into the SBA-15, carbonization of the sucrose, and finally etching of the silica template.

Nitrogen-doped porous carbon is commonly prepared in two ways: in situ synthesis or a post-treatment functionalization. The former method results in a homogeneous distribution of $\mathrm{N},{ }^{15}$ while with the latter it is difficult to control the nitrogen content and there is a risk of blocking the porous architecture. ${ }^{21}$ Xiao et al. successfully prepared nitrogen-doped microporous 
carbon with 25.0 at\% nitrogen content for detection of $\mathrm{Cd}(\mathrm{II})$ and $\mathrm{Pb}$ (II) by in situ doping of nitrogen. ${ }^{22}$

In summary, traditional methods for the synthetic of NMC materials are typically tedious and time-consuming, therefore we describe a facile one-step template-free method to prepare NMC via carbonization of a protic salt $\left([p \mathrm{PDA}]\left[2 \mathrm{HSO}_{4}\right]\right),{ }^{19}$ which behaves as an carbon and nitrogen source during pyrolysis. We then use the prepared NMC in an electrochemical heavy metal sensor. The synthetic action of Nafion and bismuth on the NMC makes the sensor highly sensitive, and we show that it can be probed by simultaneous detection of $\mathrm{Cd}(\mathrm{II})$ and $\mathrm{Pb}(\mathrm{II})$.

\section{Experimental section}

\subsection{Chemicals and apparatus}

All chemicals used in this study were of analytical grade and used as received. $p$-Phenylenediamine and $\mathrm{H}_{2} \mathrm{SO}_{4}$ were obtained from Aladdin (Shanghai, China). $5.0 \mathrm{wt} \%$ Nafion, $1000 \mathrm{mg} \mathrm{\textrm {L } ^ { - 1 }}$ Cd(II) solution and $1000 \mathrm{mg} \mathrm{L}^{-1} \mathrm{~Pb}$ (II) solution were purchased from Sigma-Aldrich (Shanghai, China). $1000 \mathrm{mg} \mathrm{L}^{-1}$ atomic absorption standard Bi(III) solution was provided from Fluka (Shanghai, China).

The morphology of NMC was characterized by a field emission scanning electron microscope (SEM, Carl Zeiss, Oberkochen, Germany). X-ray photoelectron spectra (XPS) were recorded with an Axis Ultra DLD electron spectrometer (Kratos Analytical Ltd., Manchester, UK). The structure analysis of NMC was operated on JEOL-2100F microscope (JEOL, Tokyo, Japan) at $200 \mathrm{kV} . \mathrm{N}_{2}$ adsorption-desorption isotherms was determined with an Autosorb-IQ-MP gas sorption analyzer (Quantachrome Instruments, Boynton Beach, Florida USA). The content of Cd(II) and $\mathrm{Pb}$ (II) was measured with Inductively Coupled Plasma-Mass Spectrometry (ICP-MS, ELAN DRC II, PerkinElmer, USA).

\subsection{Synthesis of NMC and order mesoporous carbon}

The NMC was prepared following a published method. ${ }^{19}$ Briefly, dilute aqueous sulfuric acid solution $(20 \%, 25 \mathrm{~mL})$ was slowly dropped into methanol $(100 \mathrm{~mL})$ containing $p$-phenylenediamine $(5 \mathrm{~g})$ in an ice bath. A precipitate was instantly formed, following which the mixture was stirred for $1 \mathrm{~h}$. Afterwards the solvent was removed by using a rotary evaporator and the obtained mixture was kept at $80{ }^{\circ} \mathrm{C}$ for $24 \mathrm{~h}$ in a vacuum drying oven to get the protic salt. The as-obtained precursor was heated up to $900{ }^{\circ} \mathrm{C}$ at $10{ }^{\circ} \mathrm{C} \mathrm{min}^{-1}$ in argon atmosphere and maintained at $900{ }^{\circ} \mathrm{C}$ for $2 \mathrm{~h}$. After cooling down, black NMC was obtained. In order to compare the electrochemical performance of $\mathrm{N}$ doping, order mesoporous carbon (OMC) was prepared by using SBA-15 sacrifice template method. ${ }^{23}$

\subsection{Preparation of NMC-Nafion/GCE, NMC-Nafion-Bi/GCE and DPASV test}

The surface of GCE was sequentially polished with decreasing particle sizes of alumina power slurries. After polishing, the GCE was sonicated with absolute ethanol and deionized water for $3 \mathrm{~min}$, respectively, and then dried by nitrogen. NMC was dispersed in DMF solution (containing $0.3 \mathrm{wt} \%$ Nafion) by sonication to get a $1.0 \mathrm{mg} \mathrm{mL} \mathrm{m}^{-1}$ suspension. A NMC-Nafion/ GCE was obtained by casting $5 \mu \mathrm{L}$ of suspension on GCE surface and drying at room temperature. Meanwhile, NMCNafion-Bi/GCE was prepared by an in situ plating of Bi film in accumulation step.

The electrolyte $(10 \mathrm{~mL})$ included acetate buffer $(0.1 \mathrm{M}, \mathrm{pH}=$ 5.0) and the target metal ions. If the modified electrodes need to deposit Bi film, $400 \mu \mathrm{g} \mathrm{\textrm {L } ^ { - 1 }} \mathrm{Bi}(\mathrm{III})$ is added into the electrolyte. Under optimized conditions, differential pulse anodic stripping voltammetry (DPASV) was applied for heavy metals determination. The accumulation step was set at $-1.1 \mathrm{~V}$ under stirring for 420 s. Following the preconcentration, the solution was kept quiet for $10 \mathrm{~s}$. Then the DPASV curve was recorded at differential pulse mode from $-1.0 \mathrm{~V}$ to $-0.4 \mathrm{~V}$.

\section{Results and discussion}

\subsection{Characterization of NMC}

The granular morphology of synthesized NMC nanoparticles was characterized by SEM (Fig. 1a), revealing a fluffy foamy NMC structure. The structure NMC was evaluated by TEM as that shown in Fig. 1b. As expected, NMC is pretty transparent due to its rich, disordered wormlike porous structure, as previously reported in the literature. ${ }^{19}$

The pore structure of NMC was explored by nitrogen adsorption-desorption experiments. As presented in Fig. 1c, a hysteresis loop at pressures $P / P_{0}>0.5$ is observed, which indicates the presence of mesopores. The BET surface area is calculated to be up to $596 \mathrm{~m}^{2} \mathrm{~g}^{-1}$ with a narrow pore-size distribution and an average pore size of $7.0 \mathrm{~nm}$ as shown as in the inset of Fig. 1c.

To investigate the chemical valence and elemental composition of the NCM, XPS measurement was performed in the region from 0 to $600 \mathrm{eV}$. The elemental content of NMC is determined to 84.2 at\% for C, 10.0 at\% for N, 5.0 at\% for O, and 0.9 at\% for $\mathrm{S}$ (Fig. 1d). The high resolution $\mathrm{N} 1 \mathrm{~s}$ spectra of NMC (inset in Fig. 1d) could be deconvoluted into four peaks, at 397.80, 400.08, 402.16, and $405.05 \mathrm{eV}$, which correspond to pyridine-like, pyrrolelike nitrogen as well as oxidized species at higher binding energies $(>402 \mathrm{eV}),{ }^{24-26}$ respectively. The XPS results clearly prove that $\mathrm{N}$
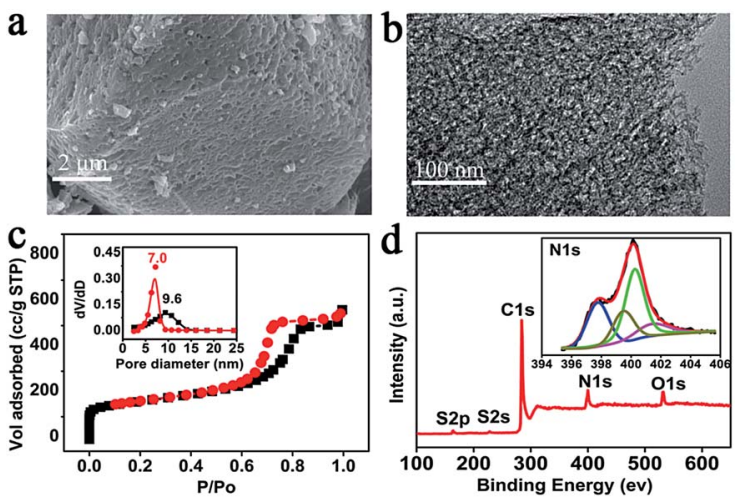

Fig. 1 (a) SEM and (b) TEM image of NMC, (c) the relative $\mathrm{N}_{2}$ sorption isotherms (inset: pore width distribution of NMC), and (d) XPS (inset: high-resolution $\mathrm{N}$ 1s spectrum). 

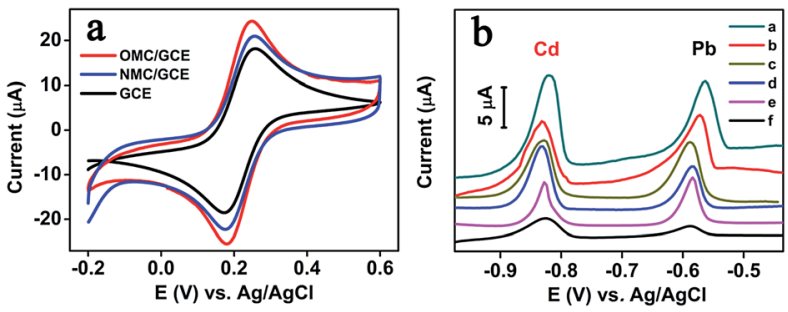

Fig. 2 (a) Comparison of cyclic voltammograms at bare GCE, OMC/ GCE and NMC/GCE with a scan rate of $50 \mathrm{mV} \mathrm{s}^{-1}$ in $1 \mathrm{mM}\left[\mathrm{Fe}(\mathrm{CN})_{6}\right]^{3-/}$ ${ }^{4-}$ and $0.1 \mathrm{M} \mathrm{KCl}$. (b) DPASV curves at different electrodes after background subtracting in $\mathrm{HAc}-\mathrm{NaAc}$ buffer $(0.1 \mathrm{M}, \mathrm{pH}$ 5.0) with $50 \mu \mathrm{g}$ $\mathrm{L}^{-1} \mathrm{Cd}(॥), 50 \mu \mathrm{g} \mathrm{L}^{-1} \mathrm{~Pb}(॥)$.

atoms have been successfully doped into the material. $\mathrm{N}$ introduction can accelerate the electron transfer and improves the sensitivity of the modified electrode. ${ }^{27}$

\subsection{Electrochemical responses of the different electrodes}

In order to study the electrochemical performance of bare GCE, OMC/GCE and NMC/GCE, cyclic voltammograms were investigated in $\mathrm{Fe}(\mathrm{CN})_{6}{ }^{3-/ 4-}$ and $\mathrm{KCl}$ solution. As shown in Fig. 2a, three pairs of well-defined redox peaks are observed in all electrodes. Compared with the bare GCE, the redox current of OMC/GCE is increased. It is believed to result from the good electrical conductivity of OMC. However, the largest peak current is appeared at NMC/GCE, which indicates that $\mathrm{N}$ accelerates electron transfer of $\left[\mathrm{Fe}(\mathrm{CN})_{6}\right]^{3-/ 4-}$ probe and shows better performance than OMC.

The electrochemical behaviors of Nafion-GCE (curve a), Bi/ GCE (curve b), Nafion-Bi/GCE (curve c), OMC-Nafion/GCE (curve d), NMC-Nafion/GCE (curve e), and NMC-Nafion-Bi/ GCE (curve f) were investigated by DAPSV in HAc-NaAc (0.1 M, pH 5.0), respectively. As presented in Fig. 2, there are two peaks around $-0.8 \mathrm{~V}$ and $-0.6 \mathrm{~V}$, corresponding to the stripping peak of $\mathrm{Cd}$ and $\mathrm{Pb}$ at these six electrodes. The anodic peak currents of $\mathrm{Cd}$ and $\mathrm{Pb}$ at $\mathrm{Bi} / \mathrm{GCE}$ are $5.09 \mu \mathrm{A}$ and $6.31 \mu \mathrm{A}$, which is almost $45.5 \%$ and $64.3 \%$ at the NMC-Nafion-Bi/GCE. Compared to Nafion/GCE, the Nafion-Bi/GCE shows a clear increase in peak currents, ascribed to the ability of the Bi-film to form a fused alloy with $\mathrm{Cd}$ and $\mathrm{Pb}(\mathrm{Cd}(\mathrm{II})+\mathrm{Bi}(\mathrm{III})+5 \mathrm{e} \rightarrow \mathrm{Cd}-$ $\mathrm{Bi}, \mathrm{Pb}(\mathrm{II})+\mathrm{Bi}(\mathrm{III})+5 \mathrm{e} \rightarrow \mathrm{Pb}-\mathrm{Bi}) .{ }^{28}$ Additionally, the stripping peak currents of $\mathrm{Cd}$ (II) and $\mathrm{Pb}$ (II) at NMC-Nafion/GCE are higher than OMC-Nafion/GCE, which suggests that NMC shows more outstanding analytical performance in determination heavy metals than OMC. Moreover, the peak current of NMC-Nafion$\mathrm{Bi} / \mathrm{GCE}$ improves about $47 \%$ for $\mathrm{Cd}$ (II) and $66 \%$ for $\mathrm{Pb}$ (II) than that of Nafion-Bi/GCE, respectively. These improvements in peak current can be attributed to the porous structure and large surface area of the NCM, which is beneficial for an effective accumulation of heavy metal ions.

\subsection{Optimization of experimental conditions}

In order to obtain high sensitive of detection heavy metals at the NMC-Nafion-Bi/GCE, pH of solution, Bi(III) concentration,
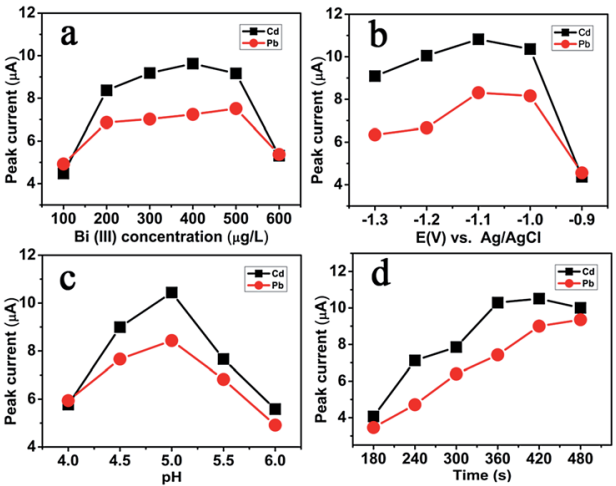

Fig. 3 Influence of various experimental parameters on stripping responses of $50 \mu \mathrm{g} \mathrm{L}^{-1} \mathrm{Cd}(॥)$ and $50 \mu \mathrm{g} \mathrm{L}^{-1} \mathrm{~Pb}(॥)$ at NMC-Nafion-Bi/ GCE. (a) Bi(III) concentration; (b) preconcentration potential; (c) pH and (d) deposition time.

accumulation potential and preconcentration time were investigated, respectively.

The effect of $\mathrm{Bi}(\mathrm{III})$ concentration was examined from $100 \mu \mathrm{g}$

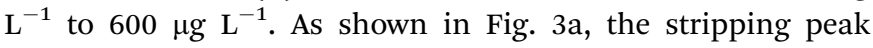
currents of $\mathrm{Cd}(\mathrm{II})$ is gradually decreased when the $\mathrm{Bi}(\mathrm{III})$ concentration was higher than $400 \mu \mathrm{g} \mathrm{L}^{-1}$ and $\mathrm{Pb}$ (II) concentration is higher than $500 \mu \mathrm{g} \mathrm{L} \mathrm{L}^{-1}$. Thus, we chose $400 \mu \mathrm{g} \mathrm{\textrm {L } ^ { - 1 }}$ $\mathrm{Bi}(\mathrm{III})$ as the optimum concentration.

The influence of deposition potentials on the DPASV signals of $\mathrm{Pb}$ (II) and $\mathrm{Cd}$ (II) was explored in the potential window from -0.9 to $-1.3 \mathrm{~V}$. The results displayed in Fig. $3 \mathrm{~b}$ indicate that the stripping peak currents increase sharply when the accumulation potential is shifted negatively from -0.9 to $-1.1 \mathrm{~V}$, and the maximum current for these two ions are at $-1.1 \mathrm{~V}$ and then shift further in the negative direction when the deposition potential is further decreased. This phenomenon is ascribed to the significant hydrogen evolution at more negative potentials. ${ }^{29}$ Here $-1.1 \mathrm{~V}$ is selected as the optimized deposition potential.

Solution $\mathrm{pH}$ can also affect the DPASV peak current of the $\mathrm{Cd}$ (II) and $\mathrm{Pb}$ (II) oxidation. Fig. 3c presents the influence of buffer $\mathrm{pH}$ on the DPASV responses of $\mathrm{Cd}$ (II) and $\mathrm{Pb}$ (II). When the $\mathrm{pH}$ increases from 4.0 to 5.0, both stripping peak currents increase, while a further increase in $\mathrm{pH}$ leads to a decrease in stripping signal. This is ascribed to the formation of metal hydroxide complexes. ${ }^{1}$ Therefore, a pH 5.0 was applied in this work.

Accumulation time is a really important parameter to heavy metal detection by using DPASV method. It can be seen from Fig. 3d, the influence of the accumulation time on detection of $\mathrm{Cd}(\mathrm{II})$ and $\mathrm{Pb}(\mathrm{II})$ was investigated from 180 to $480 \mathrm{~s}$. The stripping signals increase gradually to the deposition time from 180 up to $420 \mathrm{~s}$. However, when the preconcentration time is beyond $420 \mathrm{~s}$, the stripping peak currents almost remain constant due to the rapid surface saturation. ${ }^{30}$ In order to get high peak current, an accumulation time $420 \mathrm{~s}$ is chosen for further study.

\subsection{Analytical performance of $\mathrm{Cd}$ (II) and $\mathrm{Pb}$ (II) analysis}

The DPASV curve of $\mathrm{Cd}$ (II) and $\mathrm{Pb}$ (II) are showed in Fig. 4a. It can be seen that for $\mathrm{Cd}$ and $\mathrm{Pb}$, the potential peak positions are 


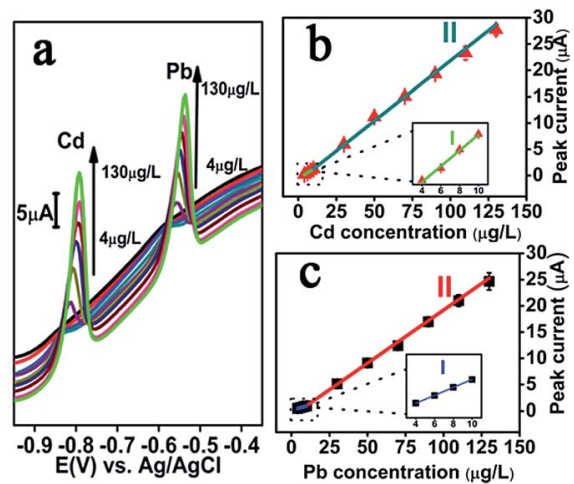

Fig. 4 (a) DPASV records for various concentrations $(4,6,8,10,30,50$, $70,90,110$ and $130 \mu \mathrm{g} \mathrm{L}^{-1}$ from bottom to top) of $\mathrm{Cd}(॥)$ and $\mathrm{Pb}(॥)$ at NMC-Nafion-Bi/GCE. (b and c) The calibration curves of Cd(॥) and $\mathrm{Pb}(I)$.

positively shifted for higher concentrations, a phenomenon which is common and analogous to what is observed for metal film electrodes. ${ }^{13}$ This is caused by interaction between the specific composition/structural morphology on the electrode surface and the thin mercury or Bi film. ${ }^{31}$

Under the optimized experimental conditions, NMCNafion-Bi/GCE was applied in the successive analysis of Cd(II)

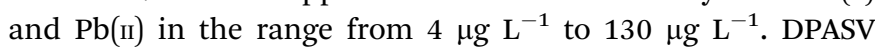
response signal $(v s . \mathrm{Ag} / \mathrm{AgCl})$ for different concentrations of target metal ions and the relative calibration plots were illustrated in Fig. $4 \mathrm{~b}$ and c. The analytical curves both for $\mathrm{Cd}(\mathrm{II})$ and $\mathrm{Pb}$ (II) cover two linear ranges from 4 to $10 \mu \mathrm{g} \mathrm{L}^{-1}$ and from 10 to $130 \mu \mathrm{g} \mathrm{L}^{-1}$, demonstrating the good linearity of the proposed sensing electrode for both $\mathrm{Cd}(\mathrm{II})$ and $\mathrm{Pb}$ (II). The regression equation of $\mathrm{Cd}(\mathrm{II})$ and $\mathrm{Pb}$ (II) are listed in Table 1. As seen from the Table 1, the slop of the linear in the low concentration range is much smaller than the one in the high concentration range. It could be due to the difference in rate determining step in these two concentration ranges. Moreover, the limit of detection (at S/ $\mathrm{N}=3$ ) were valuated to be $0.3 \mu \mathrm{g} \mathrm{L}^{-1}$ for $\mathrm{Cd}(\mathrm{II})$ and $0.4 \mu \mathrm{g} \mathrm{L}^{-1}$ for $\mathrm{Pb}$ (II), which are 10 times for $\mathrm{Cd}$ (II) and 25 times for $\mathrm{Pb}$ (II) lower than the reference value of drinking water given by WHO (Cd: 3 $\left.\mu \mathrm{g} \mathrm{L} \mathrm{L}^{-1}, \mathrm{~Pb}: 10 \mu \mathrm{g} \mathrm{L}^{-1}\right),{ }^{32}$ making the NMC-Nafion-Bi/GCE to a good candidate for the analysis of real aqueous samples.

The sensing performance of NMC-Nafion-Bi/GCE towards $\mathrm{Cd}(\mathrm{II})$ and $\mathrm{Pb}$ (II) is compared with the other reported sensors and presented in Table 2. It is obvious that the proposed NMCNafion-Bi/GCE is comparable to the previously reported results.

\subsection{Interference study}

The co-exiting ions test was applied by adding different cations into $0.1 \mathrm{M} \mathrm{HAc}-\mathrm{NaAc}$ solution containing both $50 \mu \mathrm{g} \mathrm{L} \mathrm{L}^{-1} \mathrm{Cd}(\mathrm{II})$ and $50 \mu \mathrm{g} \mathrm{L}^{-1} \mathrm{~Pb}(\mathrm{II})$. Fig. 5 presents the DPASV peak current comparison of $\mathrm{Cd}$ (II) and $\mathrm{Pb}$ (II) in the absence $\left(I_{0}\right)$ and presence (I) of various interfering metal ions. As displayed, under $\pm 10.0 \%$ tolerated ratios, 600 -fold $\mathrm{Ca}$ (II), 200 -fold $\mathrm{Mg}$ (II), 50 -fold $\mathrm{Zn}$ (II), 10-fold Fe(II), 8-fold Al(III), 8-fold $\mathrm{Cr}$ (III), 5-fold Fe(III), and 5 -fold $\mathrm{Co}$ (III) have a relatively small influence of the peak current of $\mathrm{Cd}$ (II) and $\mathrm{Pb}$ (II). However, it is found that $\mathrm{Cu}$ (II) will seriously affect the stripping current of $\mathrm{Cd}(\mathrm{II})$ and $\mathrm{Pb}$ (II), which was in line with ref. 41 . When 1-fold of $\mathrm{Cu}(\mathrm{II})$ is added, the peak current of $\mathrm{Cd}(\mathrm{II})$ and $\mathrm{Pb}$ (II) decreased by $55.4 \%$ and $63.2 \%$, respectively, owing to the formation of $\mathrm{Cu}-\mathrm{Pb}$ and $\mathrm{Cu}-\mathrm{Cd}$ alloy. ${ }^{33}$

\subsection{Repeatability, reproducibility and stability of the sensor}

Repeatability was evaluated by five measurements of $50 \mu \mathrm{g} \mathrm{L}^{-1}$ $\mathrm{Cd}(\mathrm{II})$ and $50 \mu \mathrm{g} \mathrm{L}^{-1} \mathrm{~Pb}$ (II) at the same NMC-Nafion-Bi/GCE. The relative standard deviations (RSD) based on five times measures were $3.7 \%$ for $\mathrm{Cd}(\mathrm{II})$ and $3.5 \%$ for $\mathrm{Pb}(\mathrm{II})$, indicating a satisfying durability of the developed electrode.

Reproducibility of the proposed electrode was carefully examined by using five NMC-Nafion-Bi/GCE for simultaneous detection of $50 \mu \mathrm{g} \mathrm{L}^{-1} \mathrm{Cd}(\mathrm{II})$ and $50 \mu \mathrm{g} \mathrm{L}^{-1} \mathrm{~Pb}(\mathrm{II})$. The RSD between electrodes was $3.3 \%$ for $\mathrm{Cd}(\mathrm{II})$ and $5.4 \%$ for $\mathrm{Pb}$ (II), respectively.

After storage at $4{ }^{\circ} \mathrm{C}$ for one day and half a month, the stripping signal stability of NMC-Nafion-Bi/GCE was evaluated

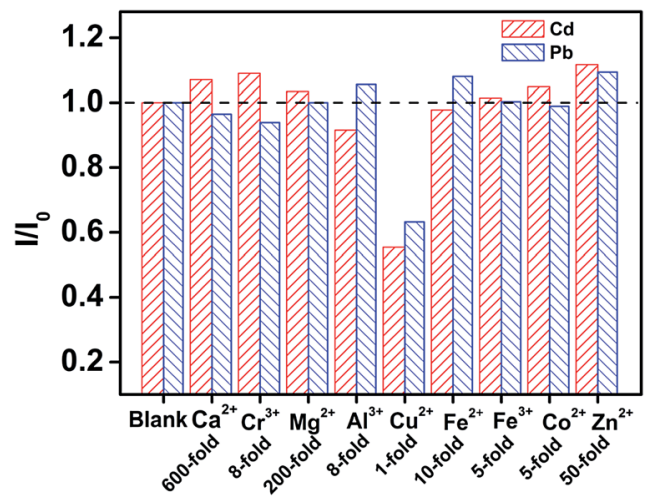

Fig. 5 Interferences caused by other cations on the stripping peak current of $50 \mu \mathrm{g} \mathrm{L}^{-1} \mathrm{Cd}(॥)$ (red) and $50 \mu \mathrm{g} \mathrm{L}^{-1} \mathrm{~Pb}(॥)$ (blue) under the optimized conditions.

Table 1 Analytical characteristics obtained for the developed sensor and the maximum acceptable content for drinking water recommended by World Health Organization

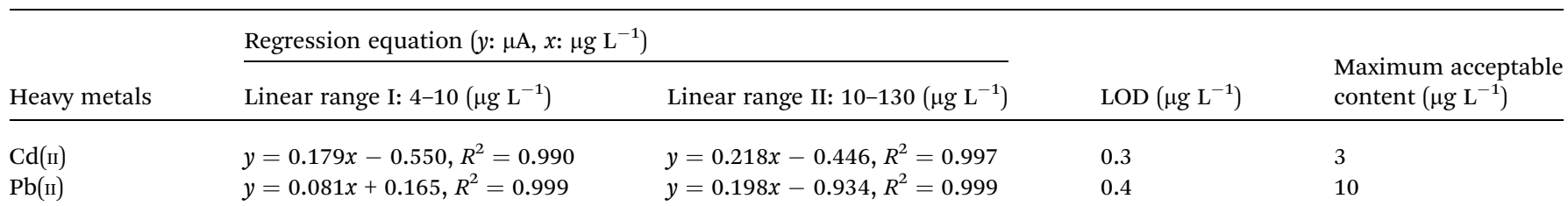


Table 2 Comparison of the analytical performance of the proposed method with others

\begin{tabular}{|c|c|c|c|c|c|c|c|}
\hline \multirow[b]{2}{*}{ Modified electrode } & \multirow[b]{2}{*}{ Method } & \multicolumn{2}{|c|}{ Range in $\mu \mathrm{g} \mathrm{L}^{-1}$} & \multicolumn{2}{|c|}{$\begin{array}{l}\text { Limit of detection } \\
\text { in } \mu \mathrm{g} \mathrm{L^{-1 }}\end{array}$} & \multirow{2}{*}{$\begin{array}{l}\text { Deposition } \\
\text { time in } \mathrm{s}\end{array}$} & \multirow[b]{2}{*}{ Ref. } \\
\hline & & $\mathrm{Cd}$ & $\mathrm{Pb}$ & Cd & $\mathrm{Pb}$ & & \\
\hline${ }^{a}$ Carbon of ZIF-8/Nafion/Bi/GCE & DPASV & $2-100$ & $0.5-100$ & 1.5 & 0.05 & 180 & 22 \\
\hline${ }^{b}$ MWCNT- $-{ }^{c}$ poly(PVC)/GCE & DPASV & $1.0-300$ & $1.0-200$ & 0.2 & 0.4 & 420 & 33 \\
\hline Nafion- $-{ }^{d} \mathrm{G}-{ }^{e} \mathrm{HgFE} / \mathrm{GCE}$ & SWASV & $1-7$ & $1-7$ & 0.08 & 0.07 & 120 & 34 \\
\hline $\mathrm{Bi}-{ }^{f}$ 24C8-Nafion $/{ }^{g}$ SPCE & SWASV & $0.5-60$ & $0.5-60$ & 0.27 & 0.11 & 180 & 35 \\
\hline MWCNTs-Nafion-Bi $/^{h}$ SPE & DPASV & $0.5-80$ & $0.05-100$ & 0.1 & 0.07 & 120 & 36 \\
\hline${ }^{i} \mathrm{ERGO}^{j}{ }^{j} \mathrm{TH} /{ }^{k} \mathrm{MES} / \mathrm{GCE}$ & SWASV & $1-40$ & $1-40$ & 0.1 & 0.05 & 300 & 37 \\
\hline Bi-Nafion- ${ }^{l}$ DMcT $-{ }^{m}$ PANI-MWCNT/GCE & DPASV & $0.02-20$ & $0.1-30$ & 0.01 & 0.04 & 360 & 38 \\
\hline${ }^{n} \mathrm{BiOCl}-\mathrm{MWCNT} / \mathrm{GCE}$ & SWASV & $5-10$ & $5-10$ & 0.57 & 1.2 & 120 & 39 \\
\hline Nafion- ${ }^{o}$ PDMcT-MWCNTs/GCE & DPASV & $0.05-20$ & $0.1-22$ & 0.03 & 0.05 & 120 & 40 \\
\hline NMC-Nafion-Bi/GCE & DPASV & $4-130$ & $4-130$ & 0.3 & 0.4 & 420 & Our work \\
\hline
\end{tabular}

${ }^{a}$ Nitrogen doped microporous carbon derived from ZIF-8. ${ }^{b}$ Multi-walled carbon nanotube. ${ }^{c}$ Poly(pyrocatechol violet). ${ }^{d}$ Graphene. ${ }^{e}$ Mercury film electrode. ${ }^{f}$ Dibenzo-24-crown-8. ${ }^{g}$ Screen-printed carbon electrode. ${ }^{h}$ Screen-printed electrode. ${ }^{i}$ Electroreduced graphene oxide. ${ }^{j}$ Thionine. ${ }^{k} 2$ Mercaptoethanesulfonate. ${ }^{l}$ 2,5-Dimercapto-1,3,4-thiadiazole. ${ }^{m}$ Polyaniline. ${ }^{n}$ Bismuth-oxychloride. ${ }^{o}$ Poly(2,5-dimercapto-1,3,4-thiadiazole).

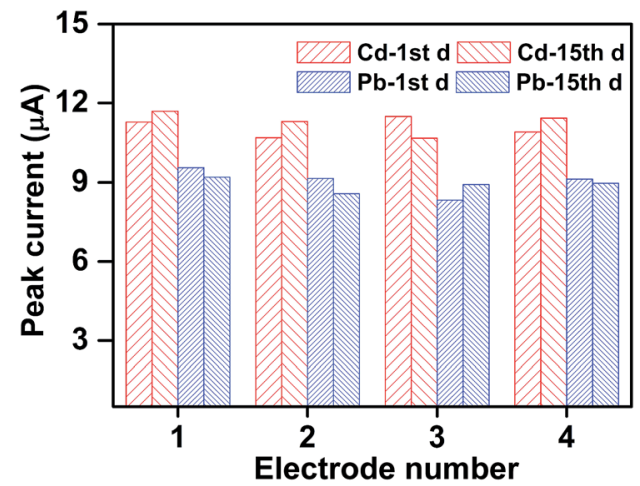

Fig. 6 Interferences caused by storage time on the DPASV responses of $50 \mu \mathrm{g} \mathrm{L}^{-1} \mathrm{Cd}(॥)$ (red) and $50 \mu \mathrm{g} \mathrm{L}^{-1} \mathrm{~Pb}(॥)$ (blue) under the optimized conditions.

in $50 \mu \mathrm{g} \mathrm{L} \mathrm{L}^{-1} \mathrm{Cd}(\mathrm{II})$ and $50 \mu \mathrm{g} \mathrm{L} \mathrm{L}^{-1} \mathrm{~Pb}(\mathrm{II})$ by comparing the striping peak current between the 1st and 15th day. As illustrated in Fig. 6, the DPASV responses of $\mathrm{Cd}(\mathrm{II})$ and $\mathrm{Pb}(\mathrm{II})$ obtained at different storage time only slightly change, implying the good long-time stability of the proposed sensor.

\subsection{Analysis of real sample}

To evaluate its accuracy in practical applications, the modified electrode was utilized to detect trace amounts of target metal

Table 3 Results of the analysis of tap water $(N=3)$

\begin{tabular}{|c|c|c|c|c|c|c|}
\hline \multirow{2}{*}{$\begin{array}{l}\text { Added } \\
\left(\mu \mathrm{g} \mathrm{L}^{-1}\right)\end{array}$} & \multicolumn{2}{|c|}{ Found $\left(\mu \mathrm{g} \mathrm{L}^{-1}\right)$} & \multicolumn{2}{|c|}{$\begin{array}{l}\text { Recovery } \\
(\%)\end{array}$} & \multicolumn{2}{|c|}{$\begin{array}{l}\text { Found by ICP- } \\
\text { MS }\left(\mu \mathrm{g} \mathrm{L}^{-1}\right)\end{array}$} \\
\hline & $\mathrm{Cd}$ & $\mathrm{Pb}$ & $\mathrm{Cd}$ & $\mathrm{Pb}$ & $\mathrm{Cd}$ & $\mathrm{Pb}$ \\
\hline 0 & - & - & - & - & - & - \\
\hline 6 & $6.5 \pm 0.1$ & $6.5 \pm 0.1$ & 108 & 108 & 6.0 & 5.8 \\
\hline 8 & $7.7 \pm 0.1$ & $8.6 \pm 0.1$ & 96 & 108 & 7.9 & 8.1 \\
\hline 30 & $28.6 \pm 0.4$ & $30.3 \pm 0.4$ & 95 & 101 & 29.7 & 29.9 \\
\hline
\end{tabular}

ions in real water sample by standard addition method. The environmental samples of tap water were collected from municipal water supply system of Urumqi. The real samples also tested by inductively coupled plasma mass spectrometry (ICP-MS) as a reference method. As listed in Table 3, the amount of $\mathrm{Cd}(\mathrm{II})$ and $\mathrm{Pb}$ (II) recovered with the help of the sensor are in good agreement with reference method.

\section{Conclusions}

A large specific surface area and good electrical conductivity NMC was obtained via direct carbonation of a single smallmolecule protic salt $[p \mathrm{PDA}]\left[2 \mathrm{HSO}_{4}\right]$. The NMC was used to make the sensitive sensor electrode for $\mathrm{Cd}(\mathrm{II})$ and $\mathrm{Pb}$ (II) detection by DPASV. In particular, the developed sensor allows the analysis of $\mathrm{Cd}(\mathrm{II})$ and $\mathrm{Pb}(\mathrm{II})$ at a more lower detection limit ( $\mathrm{Cd}(\mathrm{II}), 0.3 \mu \mathrm{g} \mathrm{L}{ }^{-1} ; \mathrm{Pb}(\mathrm{II}), 0.4 \mu \mathrm{g} \mathrm{L}^{-1}$ ). In addition, we further show that the sensor successfully passes stringent interference tests for common interfering agents, with the exception for copper, and also displays good long term stability and reproducibility. Finally we show the sensor's applicability for real-life testing of tap water section should come in this section at the end of the article, before the acknowledgements.

\section{Acknowledgements}

This work was supported by National Natural Science Foundation of China (21677171 and 21505154), Xinjiang International Science and Technology Cooperation Project (20166010), West Light Foundation of The Chinese Academy of Sciences (2016YJRC-1), 1000-Talent Program (Recruitment Program of Global Expert, In Chinese: Qian-Ren-Ji-Hua), and Director Foundation of XTIPC, CAS (Grant No. 2015RC012). TW acknowledge support from the Artificial Leaf Project Umeå (K\&A Wallenberg foundation) and by the Swedish Research Council (2013-5252). 


\section{Notes and references}

1 M. Lv, X. Wang, J. Li, X. Yang, C. a. Zhang, J. Yang and H. Hu, Electrochim. Acta, 2013, 108, 412-420.

2 P. Hajeb, J. J. Sloth, S. Shakibazadeh, N. A. Mahyudin and L. Afsah Hejri, Compr. Rev. Food Sci. Food Saf., 2014, 13, 457-472.

3 A. H. El-Sheikh, Y. S. Al-Degs, J. A. Sweileh and A. J. Said, Talanta, 2013, 116, 482-487.

4 D. V. Biller and K. W. Bruland, Mar. Chem., 2012, 130-131, 12-20.

5 P. Zhang, G. Xu, J. Lv, J. Cui, Z. Zheng and Y. Wu, J. Electroanal. Chem., 2012, 685, 91-96.

6 B. Wang, B. Luo, M. Liang, A. Wang, J. Wang, Y. Fang, Y. Chang and L. Zhi, Nanoscale, 2011, 3, 5059-5066.

7 C. Liang, Z. Li and S. Dai, Angew. Chem., 2008, 47, 3696-3717. 8 P. Kanchana, N. Sudhan, S. Anandhakumar, J. Mathiyarasu, P. Manisankar and C. Sekar, RSC Adv. , 2015, 5, 68587-68594.

9 R. Silva, D. Voiry, M. Chhowalla and T. Asefa, J. Am. Chem. Soc., 2013, 135, 7823-7826.

10 H. Zhu, J. Yin, X. Wang, H. Wang and X. Yang, Adv. Funct. Mater., 2013, 23, 1305-1312.

11 G. Hu, F. Nitze, E. Gracia-Espino, J. Ma, H. Barzegar, T. Sharifi, X. Jia, A. Shchukareev, L. Lu, C. Ma, G. Yang and T. Wagberg, Nat. Commun., 2014, 5, 5253-5261.

12 L. Zhang, K. Cai, F. Zhang and Q. Yue, Chem. Res. Chin. Univ., 2015, 31, 130-137.

13 L. Xiao, S. Zhou, G. Hu, H. Xu, Y. Wang and Q. Yuan, RSC Adv., 2015, 5, 77159-77167.

14 S. van Dommele, K. P. de Jong and J. H. Bitter, Chem. Commun., 2006, 4859-4861.

15 Y. Shao, J. Sui, G. Yin and Y. Gao, Appl. Catal., B, 2008, 79, 89-99.

16 L. Cui, J. Wu and H. Ju, ACS Appl. Mater. Interfaces, 2014, 6, 16210-16216.

17 S. Tanaka, N. Nishiyama, Y. Egashira and K. Ueyama, Chem. Commun., 2005, 16, 2125-2127.

18 T. Y. Ma, L. Liu and Z. Y. Yuan, Chem. Soc. Rev., 2013, 42, 3977-4003.

19 S. Zhang, T. Mandai, K. Ueno, K. Dokko and M. Watanabe, Nano Energy, 2015, 13, 376-386.

20 H. Shen, D. Qin, Y. Li, S. Li, C. Yang, Q. Yuan, T. Wagberg and G. Hu, Electroanalysis, 2016, 12, 2939-2946.

21 Y. Zheng, Y. Jiao, M. Jaroniec, Y. Jin and S. Z. Qiao, Small, 2012, 8, 3550-3566.
22 L. Xiao, H. Xu, S. Zhou, T. Song, H. Wang, S. Li, W. Gan and Q. Yuan, Electrochim. Acta, 2014, 143, 143-151.

23 M. Armandi, B. Bonelli, E. I. Karaindrou, C. O. Areán and E. Garrone, Catal. Today, 2008, 138, 244-248.

24 W. Zhu, W. Liu, T. Li, X. Yue, T. Liu, W. Zhang, S. Yu, D. Zhang and J. Wang, Electrochim. Acta, 2014, 146, 419-428.

25 T. Sharifi, F. Nitze, H. R. Barzegar, C.-W. Tai, M. Mazurkiewicz, A. Malolepszy, L. Stobinski and T. Wågberg, Carbon, 2012, 50, 3535-3541.

26 J. P. Paraknowitsch, A. Thomas and M. Antonietti, J. Mater. Chem., 2010, 20, 6746.

27 S. Deng, G. Jian, J. Lei, Z. Hu and H. Ju, Biosens. Bioelectron., 2009, 25, 373-377.

28 S. Lee, S. Bong, J. Ha, M. Kwak, S.-K. Park and Y. Piao, Sens. Actuators, B, 2015, 215, 62-69.

29 A. Afkhami, H. Bagheri, H. Khoshsafar, M. Saber-Tehrani, M. Tabatabaee and A. Shirzadmehr, Anal. Chim. Acta, 2012, 746, 98-106.

30 J. Wang, Ü. A. Kirgöz and J. Lu, Electrochem. Commun., 2001, 3, 703-706.

31 Y. Wang, Y. Wu, J. Xie and X. Hu, Sens. Actuators, B, 2013, 177, 1161-1166.

32 World Health Organization, Guidelines for Drinking-water Quality, WHO chronicle, 4th edn, 2011, pp. 104-108.

33 M. A. Chamjangali, H. Kouhestani, F. Masdarolomoor and H. Daneshinejad, Sens. Actuators, B, 2015, 216, 384-393.

34 C. M. Willemse, K. Tlhomelang, N. Jahed, P. G. Baker and E. I. Iwuoha, Sensors, 2011, 11, 3970-3987.

35 K. Keawkim, S. Chuanuwatanakul, O. Chailapakul and S. Motomizu, Food Control, 2013, 31, 14-21.

36 L. Fu, X. Li, J. Yu and J. Ye, Electroanalysis, 2013, 25, 567-572. 37 Z. Li, L. Chen, F. He, L. Bu, X. Qin, Q. Xie, S. Yao, X. Tu, X. Luo and S. Luo, Talanta, 2014, 122, 285-292.

38 Z. Su, Y. Liu, Y. Zhang, Q. Xie, L. Chen, Y. Huang, Y. Fu, Y. Meng, X. Li, M. Ma and S. Yao, Analyst, 2013, 138, 11801186.

39 S. Cerovac, V. Guzsvany, Z. Konya, A. M. Ashrafi, I. Svancara, S. Roncevic, A. Kukovecz, B. Dalmacija and K. Vytras, Talanta, 2015, 134, 640-649.

40 X. He, Z. Su, Q. Xie, C. Chen, Y. Fu, L. Chen, Y. Liu, M. Ma, L. Deng, D. Qin, Y. Luo and S. Yao, Microchim. Acta, 2011, 173, 95-102.

41 Z. Wang, H. Wang, Z. Zhang, X. Yang and G. Liu, Electrochim. Acta, 2014, 120, 140-146. 